\title{
Improving the Properties of Self-compacted Concrete with Using Combined Silica Fume and Metakaolin
}

\author{
Mohammad Kazem Sharbatdar ${ }^{1 *}$, Mohammad Abbasi ${ }^{1}$, Pouyan Fakharian ${ }^{1}$ \\ 1 Faculty of Civil Engineering, Semnan University, Semnan, 35131-1911, Iran \\ * Corresponding author, e-mail: msharbatdar@semnan.ac.ir
}

Received: 09 September 2017, Accepted: 06 March 2020, Published online: 14 April 2020

\begin{abstract}
The viscosity is the main property of self- compacted concrete (SCC) and using of pozzolan material such as metakaolin (MK) and Silica fume (SF) can help to achieve that goal. The effect of simultaneous substitution of MK and SF instead of cement on the rheological and mechanical properties of self-compacted concrete was experimentally investigated in this paper. Seventeen mix designs were cast with a substitution weight percentage $(5,10,15,20 \%)$ in water to adhesive material ratio equal 0.32 . All mixes were examined by compressive, tensile strengths and water absorption tests with an appropriate fluidity, without having signs of segregation or instability. The test results were indicated that the SCC mixes containing MK and SF had higher compressive and tensile strengths in comparison with no-pozzolan concrete. The comparison of linear multiple regression techniques (LMRT) and nonlinear multiple regression technique outputs with experimental results showed an appropriate similarity.
\end{abstract}

Keywords

metakaolin, silica fume (SF), self-compacted concrete, hardened properties

\section{Introduction}

Self-compacted concrete is used in in-cast and pre-cast concrete causes less noise and saving in skilled labor [1]. Studies are indicating that a self-compacted concrete could be reached by changing the ratio of mixed materials with more compressive and bending than an ordinary concrete [2]. Self-compacted concrete includes a wide range of mix design that provides the properties of fresh and hardened concrete necessary for special uses. Although strength is the original criterion of this concrete, the properties of its fresh concrete are much more widespread than ordinary concrete and the ones compacted by shakers. Generally self-compacted concrete has the same basic components as ordinary concrete and the high fluidity one. Usually, self-compacted concrete includes a high amount of cement and less water-cement ratio than ordinary concrete and can provide a high level of strength [3]. Selfcompacted concrete is one of concrete type could be made up by the use of Silica fume (SF). Recently, self-compacted concrete is used widely, due to its special properties [4]. This type of concrete is placed in concrete mold only by its self-weight and doesn't need to vibration [5] and keeps its adhesion without bleeding and segregation [6]. Metakaolin is another material that is used as a substitution of cement in concrete, due to its pozzolan properties. Metakaolin is a shapeless material made of layer elements. In producing metakaolin, kaolin clay is the input raw material. Kaolin is a small mineral material, traditionally used in the Chinese dish [7]. Although metakaolin is expensive, it is affordable because of its effects on concrete resistance. Use of metakaolin causes an increase in the amount of compressive resistance [8], viscosity and yield stress in concrete. On the other hand, the usage of high percent metakaolin instead of cement decreases the fluidity [9]. In addition, metakaolin can reduce the concrete shrinkage [10] and chloride influence [11]. Several experimental tests were conducted to investigate the effects of increasing and adding of silica fume to mechanical and different strengths of concrete such as compressive, tensile and impact resistance [12-14]. In fact, Silica fume (SF) increases the cement cohesion and compressive resistance because it has a higher specific surface than metakaolin and cement, other studies confirmed these results and indicated that the use of metakaolin and Silica fume (SF) could increase the compressive resistance $[9,15-17]$. Several experimental 
researches were conducted in recent years to investigate the effect of regular, volcanic, waste aggregate materials on different properties of self-compacted concrete [18-21]. Although there are acceptable studies about Silica fume (SF) and metakaolin, but there is only limited studied about the use of both of them simultaneously. The research target is to evaluate self-compacted concrete containing Silica fume (SF) and metakaolin according to hardened concrete tests such as compressive, tensional strengths and water absorption. Given the country's need and optimum use of materials and reduced cement consumption, we needed to achieve these goals by using new alternative materials. And this article is in this regard.

\section{Experimental details}

\subsection{Material}

In this study, gravel aggregate with maximum size $12 \mathrm{~mm}$ and $2.6 \mathrm{~g} / \mathrm{cm}^{3}$ apparent specific weight and $1 \%$ water absorption was used. The gravel grading curve was according to ASTM C33. The sand used in the study was with nominal size 0 to $6 \mathrm{~mm}$ and $2.65 \mathrm{~g} / \mathrm{cm}^{3}$ specific weight and $1.45 \%$ water absorption. The used sand grading was according to ASTM C33. The used cement was Portland type II with $3.15 \mathrm{~g} / \mathrm{cm}^{3}$ specific weight and fines with $0.33\left(\mathrm{~m}^{2} / \mathrm{g}\right)$. Metakaolin used had $2.6 \mathrm{~g} / \mathrm{cm}^{3}$ specific weight. Cement and metakaolin components are shown in Table 1. Moreover, the Silica fume (SF) used in the research was provided from Iran Ferroilice factory with $2200 \mathrm{~g} / \mathrm{cm}^{3}$ specific weight. This admixture was added to the concrete as a percentage of cement weight in its dry form and without water. Used Silica fume (SF) properties are shown in Table 1. Cement and Metakaoline particle size distribution is shown in Fig. 1. The superplasticizer used in this research was P10-3R and satisfied the European standards and criterions PREN 934-2.

Table 1 Chemical elements of cement material

\begin{tabular}{lccc}
\hline $\begin{array}{l}\text { Silica fume } \\
(\mathrm{SF})(\%)\end{array}$ & Metakaolin (\%) & Cement (\%) & $\begin{array}{c}\text { Chemical } \\
\text { elements }\end{array}$ \\
\hline 0.31 & 0.11 & 0.26 & $\mathrm{Na}_{2} \mathrm{O}$ \\
2.01 & 0.32 & 0.54 & $\mathrm{~K}_{2} \mathrm{O}$ \\
0.00 & 0.00 & 1.42 & $\mathrm{SO}_{3}$ \\
2.00 & 0.21 & 1.86 & $\mathrm{MgO}$ \\
1.50 & 0.20 & 63.95 & $\mathrm{CaO}$ \\
2.00 & 1.60 & 3.46 & $\mathrm{Fe}_{2} \mathrm{O}_{3}$ \\
1.00 & 42.80 & 5.55 & $\mathrm{Al}_{2} \mathrm{O}_{3}$ \\
85.00 & 52.10 & 21.46 & $\mathrm{SiO}_{2}$ \\
\hline
\end{tabular}

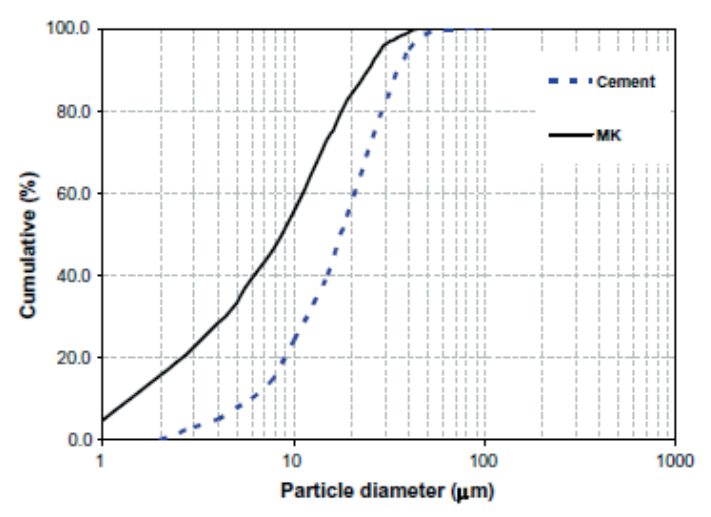

Fig. 1 Particle size distribution for binders

\subsection{Mixture proportion}

Mix designs were divided into three groups: first group called SF was including Silica fume (SF), second group called MK including metakaolin, third group called MK-SF was including simultaneous MK (metakaolin) and Silica fume (SF). The percentage of substitution of metakaolin and Silica fume (SF) for cement in all above groups were $5,10,15$, and $20 \%$. The water to adhesive material ratio was constant with the value of 0.32 in all mix designs. The design's details are shown in Table 2. At the first step of mixing the materials, sand and gravel were mixed with about the half of mix design water that lasts for 2 minutes. Afterward, the cement materials including cement, Silica fume (SF) and metakaolin and then the rest of water were added. In the next step, the superplasticizer and the viscosity modifier mixed with some water of mix design were added gradually. In the following, the details and properties of hardened concrete were presented. Silica fume and metakaolin had the equal ratio at the combined specimens.

\subsection{Test procedure}

The mechanical properties of ordinary self-compacted concrete and the containing metakaolin and Silica fume (SF) specimens was evaluated by compressive, tensional (splitting into two methods) and water absorption of standard tests. In this study, the cubic samples with $100 \mathrm{~mm}$ dimension in the age of 7, 14, 28 and 56 days were used according to ASTM C39-86 Standard in order to obtain the compressive strength. The loading speed for the compressive test was considered $0.27 \mathrm{MPa} / \mathrm{s}$. The tensional test was according to splitting cylinder into two methods and ASTM C496-90, in which $150 \mathrm{~mm}$ diameter and $300 \mathrm{~mm}$ height samples with $1.2 \mathrm{MPa} / \mathrm{s}$ speed in the age of 28 days were loaded. The water absorption was done according to ASTM C140-01 for $100 \mathrm{~mm}$ cubic samples for the 28 days- age specimens. 


\section{Experimental results and discussions}

\subsection{Compressive strength}

Table 3 shows the compressive test results in the different sample ages. The results indicated that concrete compressive strengths were raised by increasing the concrete age. The compressive strengths of samples in 7 and 56 days are shown in Fig. 2. These figures show that the use of Silica fume (SF) and specifically rising its percentage increases the compressive resistance. The simultaneous use of Silica fume (SF) and metakaolin increased the total compressive strengths. The results of Table 3 shows that rate of increasing of compressive strengths of specimens comparing to that of control specimens at the $3,7,14,28$, and 56 days $\left(f_{c u 3}, f_{c u 7}, f_{c u 14}, f_{c u 28}\right.$ and $\left.f_{c u 56}\right)$ were up to 27, 13, 20, 11, and 13 percentage, respectively for SFMK5, MK-10, SFMK10, MK-10, and SFMK10 mix designs. Generally the compressive strength of concrete with up to $10 \%$ silica fume was increased at different ages up to $14 \%$, and adding more than $10 \%$ silica fume had the negative effect on that strength and decreasing up to $30 \%$ strength with $20 \%$ silica fume. Adding metakaolin from 5 to $20 \%$ had the positive effect on compressive strengths of all mix designs and those strengths were increased up to $21 \%$. Combining of silica fume and metakaolin had more

Table 2 Mix details of MK and Silica fume (SF) concretes

\begin{tabular}{|c|c|c|c|c|c|c|c|c|c|c|c|}
\hline \multirow{2}{*}{ Mix group } & \multirow{2}{*}{ Mix. ID. } & \multirow{2}{*}{$\begin{array}{c}\text { Cement } \\
\mathrm{kg} / \mathrm{m}^{3}\end{array}$} & \multicolumn{2}{|c|}{ Metakaolin } & \multicolumn{2}{|c|}{ Silica fume(SF) } & \multirow{2}{*}{$\begin{array}{l}\text { water } \\
\mathrm{kg} / \mathrm{m}^{3}\end{array}$} & \multirow{2}{*}{$\begin{array}{c}\text { sand } \\
\mathrm{kg} / \mathrm{m}^{3}\end{array}$} & \multirow{2}{*}{$\begin{array}{l}\text { Gravel } \\
\mathrm{kg} / \mathrm{m}^{3}\end{array}$} & \multirow{2}{*}{$\begin{array}{c}\text { Severe water } \\
\text { reducer* } \\
\mathrm{kg} / \mathrm{m}^{3}\end{array}$} & \multirow{2}{*}{$\begin{array}{c}\text { The viscosity } \\
\text { modifier** } \\
\mathrm{kg} / \mathrm{m}^{3}\end{array}$} \\
\hline & & & $\%$ & $\mathrm{~kg} / \mathrm{m}$ & $\%$ & $\mathrm{~kg} / \mathrm{m}^{3}$ & & & & & \\
\hline Control & $\mathrm{C}$ & 480 & 0 & 0 & 0 & 0 & 154 & 979 & 817 & 3.51 & 1 \\
\hline \multirow{4}{*}{ SF } & SF-5 & 456 & 0 & 0 & 5 & 24 & 154 & 985 & 820 & 3.42 & 0.62 \\
\hline & SF-10 & 32 & 0 & 0 & 10 & 48 & 154 & 980 & 815 & 3.02 & 0.71 \\
\hline & SF-15 & 408 & 0 & 0 & 15 & 72 & 154 & 980 & 815 & 3.12 & 0.75 \\
\hline & SF-20 & 384 & 0 & 0 & 20 & 96 & 154 & 986 & 805 & 2.7 & 081 \\
\hline \multirow{4}{*}{ MK } & MK-5 & 456 & 5 & 24 & 0 & 0 & 154 & 987 & 820 & 3.6 & 0.6 \\
\hline & MK-10 & 432 & 10 & 48 & 0 & 0 & 154 & 987 & 815 & 3.72 & 0.7 \\
\hline & MK-15 & 408 & 15 & 72 & 0 & 0 & 154 & 980 & 815 & 3.34 & 0.76 \\
\hline & MK-20 & 384 & 20 & 96 & 0 & 0 & 154 & 989 & 805 & 2.8 & 0.85 \\
\hline \multirow{4}{*}{ SF-MK } & SF-MK5 & 456 & 2.5 & 12 & 2.5 & 12 & 154 & 985 & 825 & 2.49 & 0.79 \\
\hline & SF-MK10 & 432 & 5 & 24 & 5 & 24 & 154 & 980 & 810 & 2.43 & 0.88 \\
\hline & SF-MK15 & 408 & 7.5 & 36 & 7.5 & 36 & 154 & 984 & 810 & 2.62 & 0.98 \\
\hline & SF-MK 20 & 384 & 10 & 48 & 10 & 48 & 154 & 983 & 810 & 3.11 & 1.01 \\
\hline
\end{tabular}

Table 3 The compressive strengths results of different self-compacted concretes

\begin{tabular}{|c|c|c|c|c|c|c|c|c|c|c|}
\hline $\begin{array}{l}\text { Mixture } \\
\text { name }\end{array}$ & $f_{c u 3}(\mathrm{MPa})$ & $\frac{f_{c u 3-i}}{f_{c u 3-c t r l}}$ & $f_{c u 7}(\mathrm{MPa})$ & $\frac{f_{c u 7-i}}{f_{c u 7-c t r l}}$ & $f_{c u 14}(\mathrm{MPa})$ & $\frac{f_{c u 14-i}}{f_{c u 14-c t r l}}$ & $f_{c u 28}(\mathrm{MPa})$ & $\frac{f_{c u 28-i}}{f_{c u 28-c t r l}}$ & $f_{c u 56}(\mathrm{MPa})$ & $\frac{f_{c u 56-i}}{f_{c u 56-c t r l}}$ \\
\hline Ctrl & 20 & 1 & 33 & 1 & 35 & 1 & 45 & 1 & 53 & 1 \\
\hline SF-5 & 19 & 0.95 & 34.8 & 1.05 & 38.5 & 1.1 & 47 & 1.04 & 59.6 & 1.12 \\
\hline SF-10 & 21 & 1.05 & 36 & 1.10 & 39.8 & 1.14 & 47.3 & 1.05 & 57.8 & 1.09 \\
\hline SF-15 & 21.4 & 1.07 & 25 & 0.76 & 26.3 & 0.75 & 37.8 & 0.84 & 45.8 & 0.86 \\
\hline SF-20 & 20.8 & 1.04 & 25.7 & 0.78 & 29 & 0.83 & 31.4 & 0.70 & 42.9 & 0.81 \\
\hline MK-5 & 22 & 1.1 & 35.6 & 1.08 & 36.9 & 1.05 & 46.1 & 1.03 & 52 & 0.98 \\
\hline MK-10 & 23.9 & 1.20 & 37.2 & 1.13 & 39.3 & 1.12 & 49.8 & 1.11 & 55 & 1.04 \\
\hline MK-15 & 24.1 & 1.21 & 35.1 & 1.06 & 39.7 & 1.13 & 50.3 & 1.12 & 56.3 & 1.06 \\
\hline MK-20 & 21.3 & 1.07 & 33.6 & 1.02 & 36 & 1.03 & 46 & 1.02 & 54.6 & 1.03 \\
\hline SFMK5 & 25.3 & 1.27 & 36 & 1.09 & 36.9 & 1.05 & 46.3 & 1.03 & 53 & 1 \\
\hline SFMK10 & 24 & 1.2 & 33.5 & 1.02 & 42 & 1.20 & 49.8 & 1.11 & 60.1 & 1.13 \\
\hline SFMK15 & 21 & 1.05 & 33 & 1 & 35.6 & 0.99 & 47.3 & 1.05 & 55.8 & 1.05 \\
\hline SFMK 20 & 22 & 1.1 & 32 & 0.97 & 34.5 & 0.99 & 43.6 & 0.97 & 52.3 & 0.98 \\
\hline
\end{tabular}




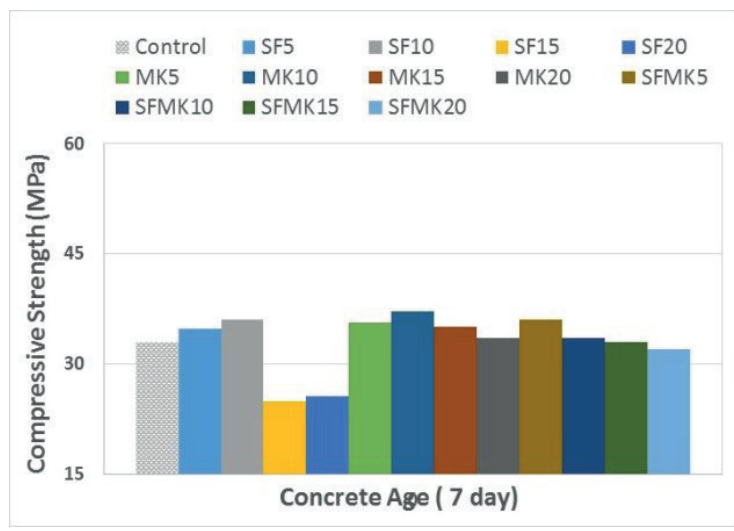

a) 7-day strengths

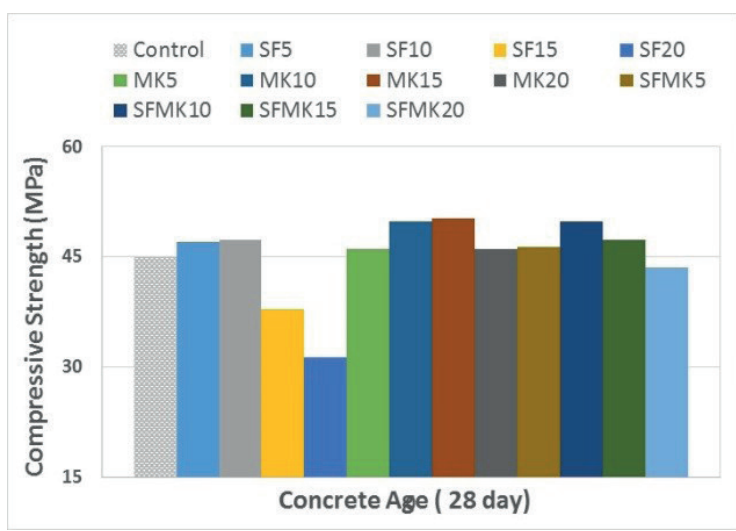

b) 28-day strengths

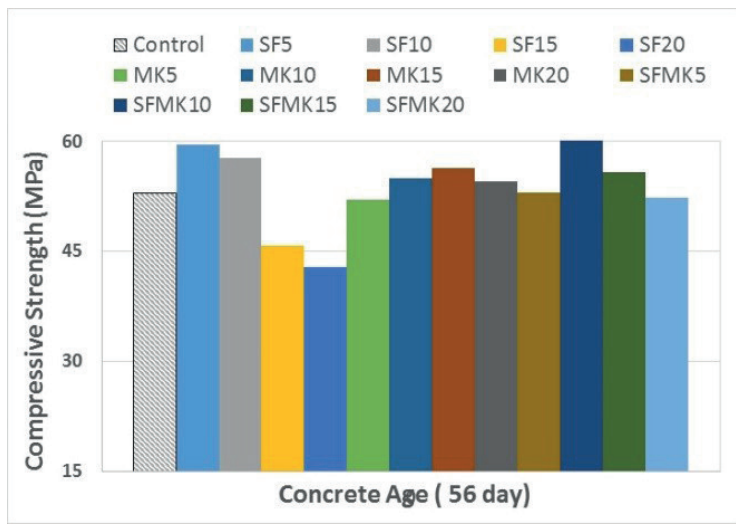

c) 56-day strengths

Fig. 2 Compressive strength of all designs

positive effect on compressive strength comparing to those strengths of individual adding of two materials, therefore those strengths were increased up to $21 \%$. The ratios of specimen strengths at different ages to 28-day strength of companion specimens is given at the Table 4 . Test results were indicated that the $3,7,14,56$-day strengths of normal concrete were 20,33, 35, $53 \mathrm{MPa}$ and ratios of respected strengths to that of 28-day strength of that concrete were $0.44,0.73,0.78$, and 1.17 , respectively.
These ratios for different concretes consisting off only silica fume, or only metakaolin and combined silica fume and metakaolin with different cementitious cements are given in Table 4. 56-day compressive strength of all design mixes were more than that of 28-day strength and was increased up to $33 \%$ for SFMK10 specimen. Even though some parts of silica fume (more than $10 \%$ ) at 28 day had negative effect and some parts of metakaolin had little positive effect at same age on compressive strength, but the 56-day strengths were significantly increased and indicating that silica fume and metakaolin participation on concrete strength were more effective after about two months. The results given in Tables 3 and 4 indicated that the specimen SFMK10 with combining $5 \%$ silica fume and $5 \%$ metakaolin showed the best mix design, its strengths at 28 and 56 days were increased up to 11 and $13 \%$ comparing to control mix design.

The test results in Table 4 indicated that the ratio of compressive strengths of ordinary concrete at 3, 7, 14, 56-day comparing to that of 28-day strength were 0.44 , $0.73,0.78$, and 1.18 , respectively. And also the results showed that all mix designs had more 56-day strength than 28-day strength up to $37 \%$ indicating that each concrete has potential to have higher strength after standard 28-day strength. It is notified that many types of concrete due to its mix design components would require reach to its final strength more than 28 days. The results also showed that silica fume and metakaolin were more active at hydration after long time instead to standard short time of 28 day, the 56 to 28-day strength ratios of ordinary, silica fume, metakaolin, and combined silica fume and metakaolin concretes were 1.18, 1.37, 1.19, and 1.21. The effect of Silica fume (SF), metakaolin, and combined materials at different age on the concrete compressive strength are shown in Fig. 2. Fig. 3 shows the strength- aging curves of different mix designs.

\subsection{Splitting tensile strength}

One of the effective factors on concrete tensile strength $\left(f_{c t}\right)$ is cement paste resistance and the cohesion between paste and aggregate. As show in Fig. 4 and Table 5, the 28-day tensile strengths $\left(f_{c t-28}\right)$ in mix designs containing only Silica fume (SF) were almost same or even less than that of ordinary concrete it means that silica fume was not positive effective on tensile strength. Also, such as compressive strength results, mix designs containing metakaolin or mixed MK and SF showed higher tensional strength because of high resistance of cement paste and the better 
Table 4 The comparison of compressive strengths of different self-compacted concretes with those of companion specimen 28-day strength

\begin{tabular}{|c|c|c|c|c|c|c|c|c|c|}
\hline $\begin{array}{l}\text { Mixture } \\
\text { name }\end{array}$ & $\begin{array}{c}f_{c u 28} \\
(\mathrm{MPa})\end{array}$ & $\begin{array}{c}f_{c u 3} \\
(\mathrm{MPa})\end{array}$ & $\frac{f_{c u 3-i}}{f_{c u 28-i}}$ & $\begin{array}{c}f_{c u 7} \\
(\mathrm{MPa})\end{array}$ & $\frac{f_{c u 7-i}}{f_{c u 28-i}}$ & $\begin{array}{c}f_{c u 14} \\
(\mathrm{MPa})\end{array}$ & $\frac{f_{\text {cu14-i }}}{f_{\text {cu28-i }}}$ & $\begin{array}{c}f_{c u 56} \\
(\mathrm{MPa})\end{array}$ & $\frac{f_{c u 56-i}}{f_{c u 28-i}}$ \\
\hline Ctrl & 45 & 20 & 0.44 & 33 & 0.73 & 35 & 0.78 & 53 & 1.18 \\
\hline SF-5 & 47 & 19 & 0.40 & 34.8 & 0.74 & 38.5 & 0.82 & 59.6 & 1.27 \\
\hline SF-10 & 47.3 & 21 & 0.44 & 36 & 0.76 & 39.8 & 0.84 & 57.8 & 1.22 \\
\hline SF-15 & 37.8 & 21.4 & 0.57 & 25 & 0.66 & 26.3 & 0.70 & 45.8 & 1.21 \\
\hline SF-20 & 31.4 & 20.8 & 0.66 & 25.7 & 0.82 & 29 & 0.92 & 42.9 & 1.37 \\
\hline MK-5 & 46.1 & 22 & 0.48 & 35.6 & 0.77 & 36.9 & 0.80 & 52 & 1.13 \\
\hline MK-10 & 49.8 & 23.9 & 0.48 & 37.2 & 0.75 & 39.3 & 0.79 & 55 & 1.10 \\
\hline MK-15 & 50.3 & 24.1 & 0.48 & 35.1 & 0.70 & 39.7 & 0.79 & 56.3 & 1.12 \\
\hline MK-20 & 46 & 21.3 & 0.46 & 33.6 & 0.73 & 36 & 0.78 & 54.6 & 1.19 \\
\hline SFMK5 & 46.3 & 25.3 & 0.55 & 36 & 0.78 & 36.9 & 0.80 & 53 & 1.14 \\
\hline SFMK10 & 49.8 & 24 & 0.48 & 33.5 & 0.67 & 42 & 0.84 & 60.1 & 1.21 \\
\hline SFMK15 & 47.3 & 21 & 0.44 & 33 & 0.70 & 35.6 & 0.75 & 55.8 & 1.18 \\
\hline SFMK20 & 43.6 & 22 & 0.50 & 32 & 0.73 & 34.5 & 0.79 & 52.3 & 1.20 \\
\hline
\end{tabular}

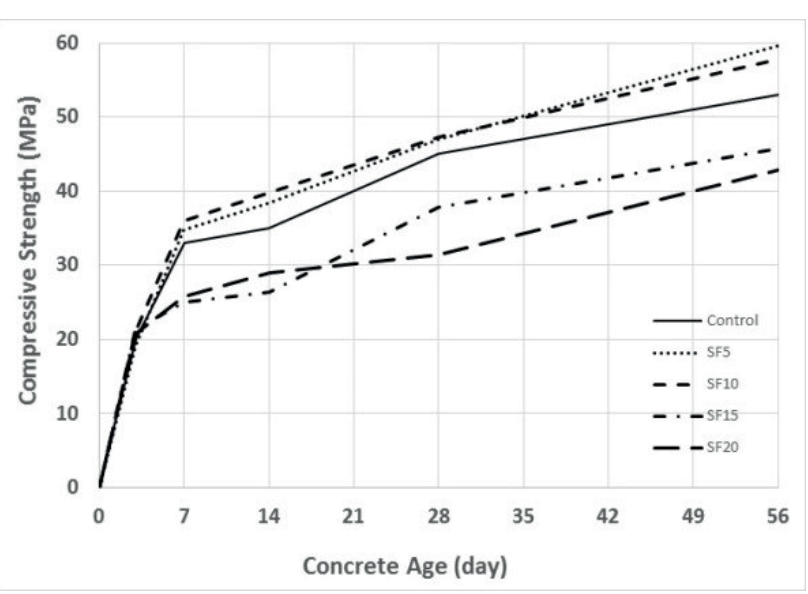

a) Comparing silica fume with Ordinary

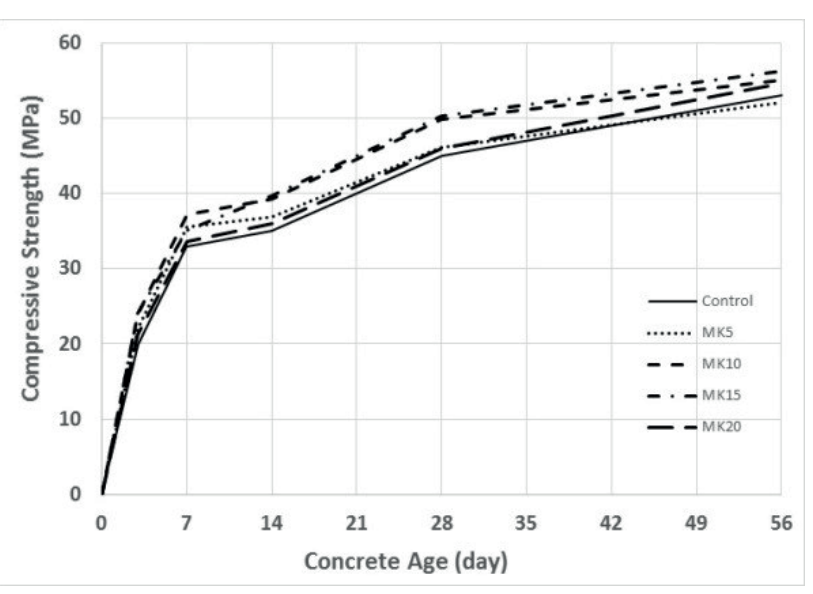

b) Comparing metakaolin with Ordinary

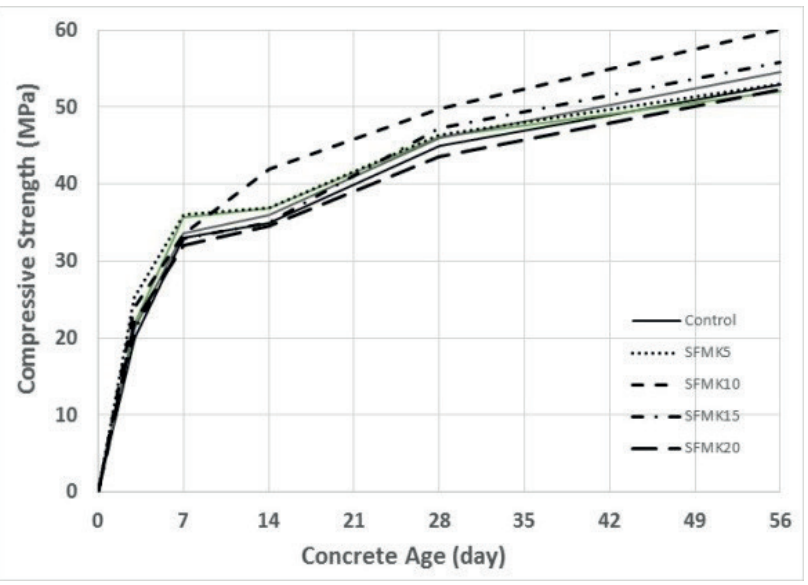

c) Comparing combined silica fume and metakaolin with Ordinary

Fig. 3 Compressive strength-aging curves of all mix designs 


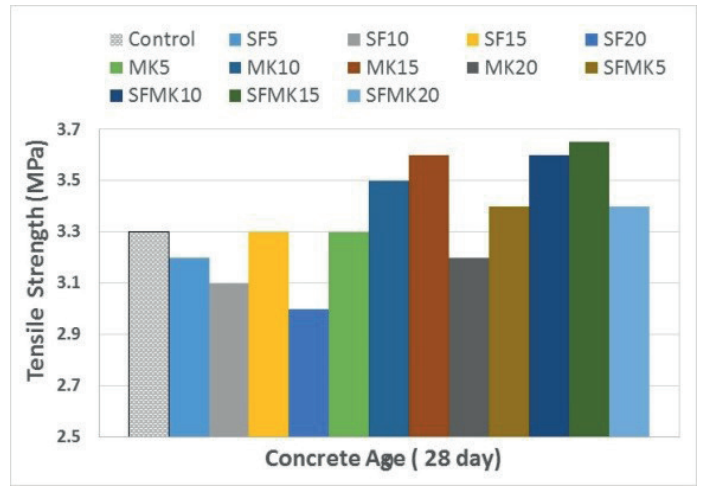

Fig. 4 28-day tensile strength of SCC

Table 5 28-day tensile strengths of self-compacted concrete

\begin{tabular}{lcc}
\hline Mix name & $\begin{array}{c}f_{c t 28} \\
(\mathrm{MPa})\end{array}$ & $\frac{f_{c t-28-i}}{f_{c t-28-c t r l}}$ \\
\hline Ctrl & 3.3 & 1 \\
SF-5 & 3.2 & 0.97 \\
SF-10 & 3.1 & 0.94 \\
SF-15 & 3.3 & 1 \\
SF-20 & 3 & 0.91 \\
MK-5 & 3.3 & 1 \\
MK-10 & 3.5 & 1.06 \\
MK-15 & 3.6 & 1.09 \\
MK-20 & 3.2 & 0.97 \\
SFMK5 & 3.4 & 1.03 \\
SFMK10 & 3.6 & 1.09 \\
SFMK15 & 3.65 & 1.1 \\
SFMK20 & 3.4 & 1.03 \\
\hline
\end{tabular}

cohesion between the paste and the concrete aggregate. By increasing the percentage of substitution metakaolin and Silica fume (SF) from $15 \%$ (SFMK15 sample) to $20 \%$ (SFMKK20 sample), the both compressive and tensile strengths were decreased. This means adding substitution filler (metakaolin and Silica fume (SF)) up to 15 percent can improve the concrete mechanical properties. More than 15 percent, although metakaolin can be used more, a decrease in concrete resistance is unavoidable because the specific surface of cement materials was decreased by increasing Silica fume (SF) present.

\subsection{Water absorption}

The water absorption tests of self-compacted concrete mix designs were conducted according to ASTM C140-01 standard. In order to achieve the exact water absorption value and its dynamic process, each mix design has been tested in 7 steps. The 28 -day age specimens were put in water for different times and the water absorption percentages were measured from minimum 30 minutes up to 3 hours submerging times during the first 6 steps and last step was done by keeping specimens in water during three days according to EFNARC [22].

Table 6 presents the results of water absorption tests. High water absorption value can influence on concrete durability because the most amount of severe corrosive factors can enter through the concrete via water. Other research results showed that concrete water absorption values were decreased due to metakaolin usage.

Table 6 Results of water absorption of self-compacted concrete

\begin{tabular}{|c|c|c|c|c|c|c|c|}
\hline \multirow{2}{*}{ Mix Design name } & \multicolumn{7}{|c|}{ Water absorption (\%) } \\
\hline & 30 minutes & 60 minutes & 90 minutes & 120 minutes & 150 Minutes & 180 minutes & 3 days \\
\hline Control & 2.1 & 2.32 & 2.58 & 2.62 & 2.66 & 2.71 & 3.26 \\
\hline SF-5 & 1.65 & 2.09 & 2.07 & 2.13 & 2.3 & 2.29 & 2.73 \\
\hline SF-10 & 1.71 & 1.92 & 1.95 & 2.11 & 2.08 & 2.25 & 2.69 \\
\hline SF-15 & 1.72 & 1.81 & 1.98 & 2.11 & 2.01 & 2.29 & 2.79 \\
\hline SF-20 & 1.59 & 1.73 & 1.75 & 1.96 & 2.05 & 2.21 & 2.62 \\
\hline MK-5 & 1.73 & 1.99 & 2.05 & 2.11 & 2.29 & 2.31 & 2.59 \\
\hline MK-10 & 1.65 & 1.72 & 1.91 & 2.01 & 2.09 & 2.19 & 2.61 \\
\hline MK-15 & 1.59 & 1.63 & 1.75 & 1.88 & 2 & 2.13 & 2.71 \\
\hline MK-20 & 1.70 & 1.73 & 1.84 & 2.27 & 1.99 & 2.24 & 2.57 \\
\hline SF-MK5 & 1.5 & 1.71 & 1.7 & 1.75 & 1.75 & 1.8 & 2.12 \\
\hline SF-MK10 & 1.51 & 1.69 & 1.76 & 1.74 & 1.76 & 1.78 & 2.21 \\
\hline SF-MK15 & 1.49 & 1.65 & 1.68 & 1.72 & 1.77 & 1.78 & 2.02 \\
\hline SF-MK20 & 1.39 & 1.64 & 1.65 & 1.76 & 1.86 & 1.75 & 1.9 \\
\hline
\end{tabular}




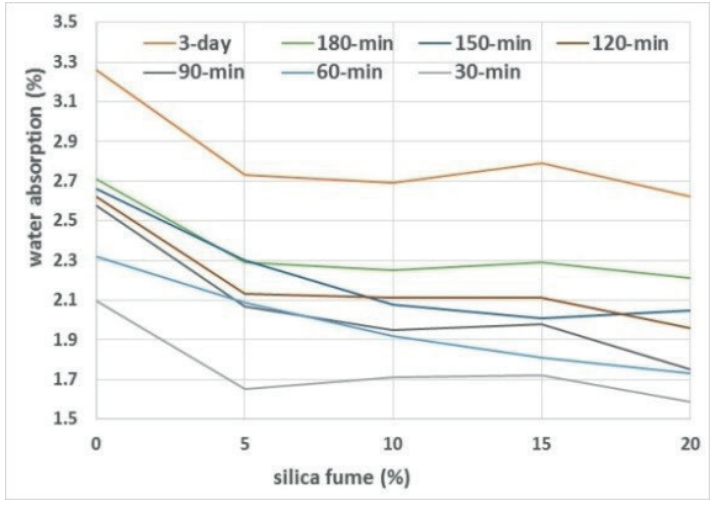

a) Containing silica fume

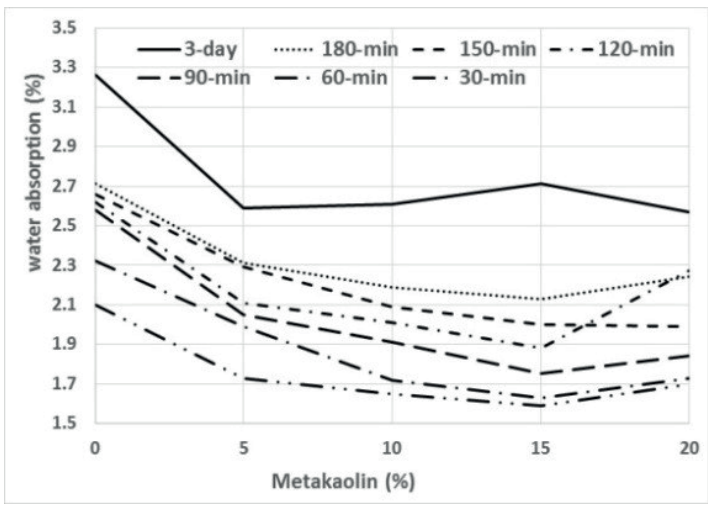

b) Containing metakaolin

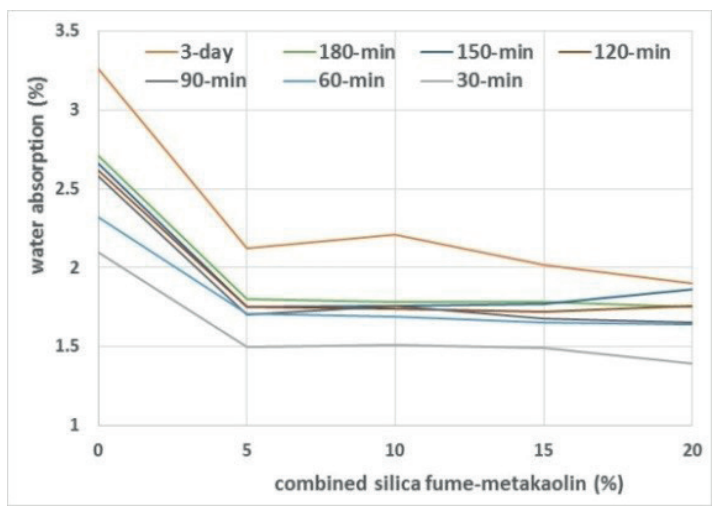

c) Containing combined silica fume and metakaolin

Fig. 5 Water absorption-material percentage curves of different submerging times of SCC

The results of water absorption of the different mix designs conducted in this paper are shown in Figs. 5-7. The more percentage of Silica fume (SF) powder can help to decrease water absorption of concretes because the specific surface of cement paste was increased by increasing of the percentage of the Silica fume (SF) in concrete. And also the percentage of water absorption was decreased in samples containing Silica fume (SF) and metakaolin by increasing the percentage of Silica fume (SF) and metakaolin. It means

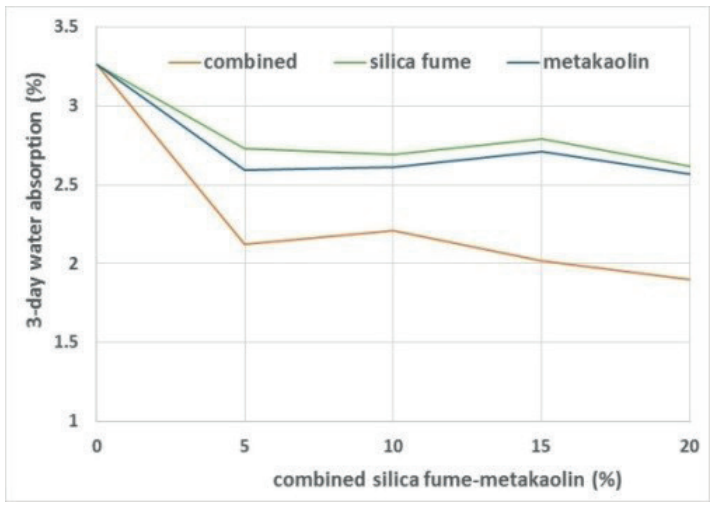

a) 3-day submerging

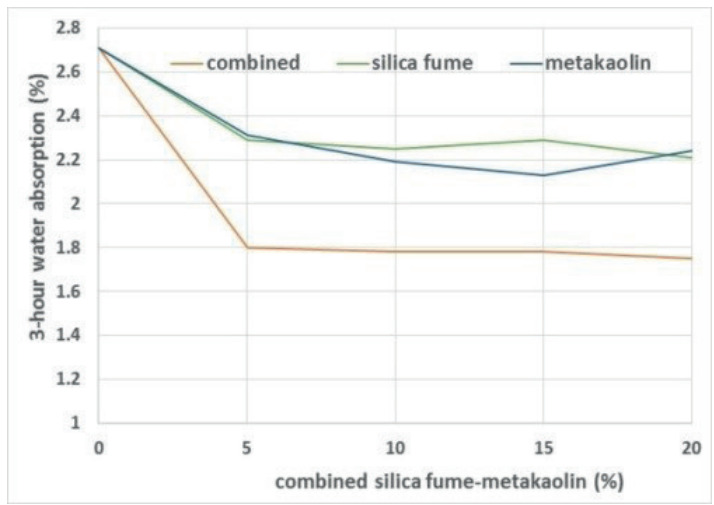

b) 3-hour submerging

Fig. 6 Comparison of water absorption percentage of different materials of SCC

that the percentage of water absorption was affected by the percentage of metakaolin and it showed a better reaction of metakaolin with cement paste. The usage of metakaolin caused a decrease in the chart dispersion (Fig. 5) and made an equal water absorption percentage in 90 to 180 -minute old samples. Average samples containing $19 \%$ metakaolin or Silica fume (SF) indicate the reduction of water absorption to control samples in different ages.

\subsection{Fresh concrete properties}

Different tests are suggested for analysis of fresh SCC concrete such as visual stability index, passing ability ratio, V-funnel, T50 time, and slump flow.

The results of these tests on 13 concrete mix design containing only silica fume, only metakaolin, and mixed silica fume and metakaolin are shown in Table 7. V-funnel and T-50 times were increased by adding more silica fume and metakaolin. Increasing rate of these times in mixed material mix design were less than those in separate material. And also slump flow was decreased by adding used materials in these tests. 


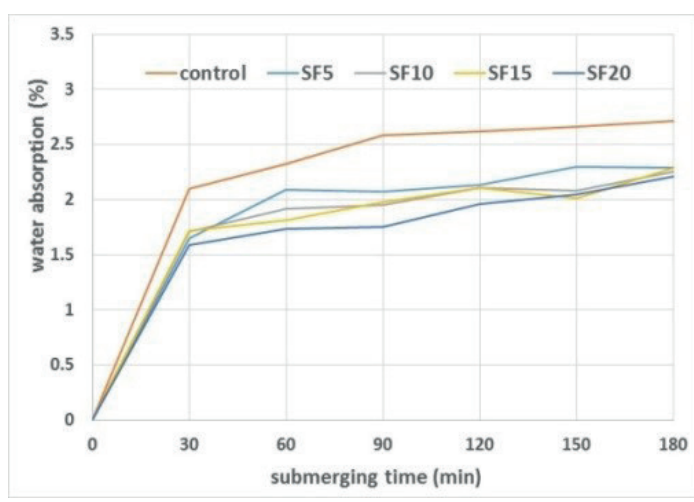

(a)

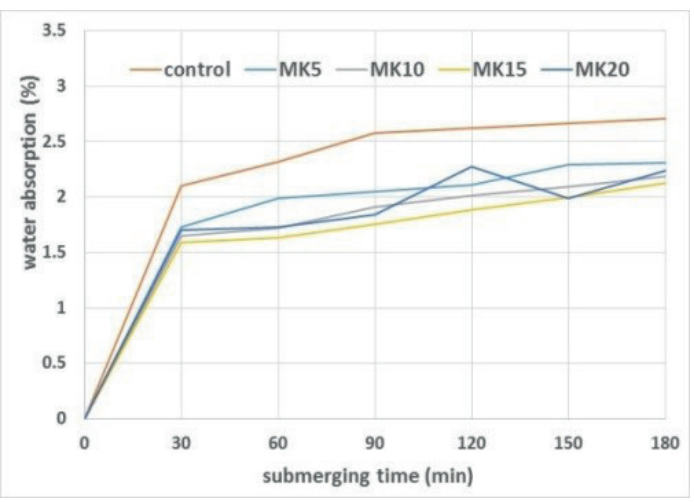

(b)

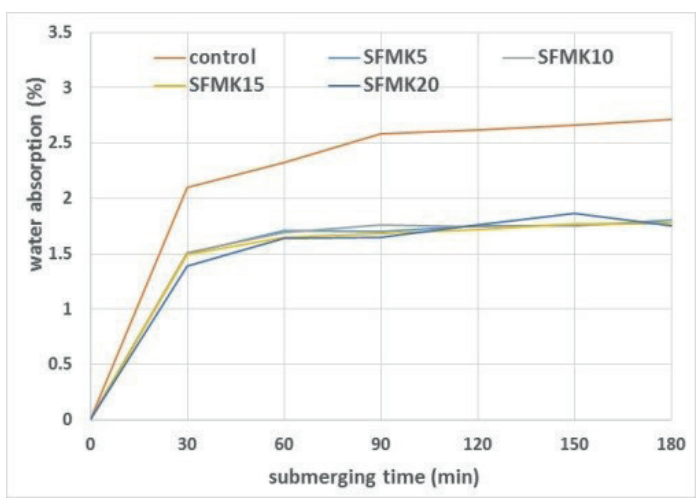

(c)

Fig. 7 Water absorption-submerging time (up to 180 minutes) curves of different materials of SCC

Table 7 The results of fresh self-compacting concrete

\begin{tabular}{|c|c|c|c|c|c|}
\hline Mix name & Visual stability index & Passing ratio & V-Funnel (s) & T50 time (s) & Slump Flow (mm) \\
\hline Ctrl & 0 & 0.89 & 6.8 & 3.2 & 710 \\
\hline SF-5 & 1 & 0.87 & 7.2 & 3.4 & 710 \\
\hline SF-10 & 1 & 0.82 & 8.9 & 3.4 & 705 \\
\hline SF-15 & 0 & 0.86 & 10.5 & 4.1 & 695 \\
\hline SF-20 & 1 & 0.78 & 10.4 & 4.2 & 695 \\
\hline MK-5 & 0 & 0.85 & 7.9 & 3.1 & 705 \\
\hline MK-10 & 1 & 0.79 & 8.9 & 3.6 & 705 \\
\hline MK-15 & 1 & 0.8 & 9.4 & 4.7 & 695 \\
\hline MK-20 & 1 & 0.74 & 11.2 & 4.8 & 690 \\
\hline SFMK5 & 0 & 0.78 & 8.6 & 4.1 & 700 \\
\hline SFMK10 & 1 & 0.74 & 9.8 & 4.3 & 690 \\
\hline SFMK15 & 0 & 0.7 & 11.3 & 5.1 & 690 \\
\hline SFMK20 & 1 & 0.68 & 11.8 & 5.3 & 675 \\
\hline
\end{tabular}

\section{Multiple regression estimations of compressive strength}

The amount of self-compacted concrete compressive strength depends on many factors. Via the use of linear regression, the compressive strength of concrete can be estimated according to each factor. But if it is aimed achieve the value of compressive strength according to all of the effective factors, an appropriate relationship among all the factors should be reached. In this paper, the linear multiple regression techniques (LMRT) and nonlinear multiple regression techniques in SPSS21 software environment is used in order to achieve an appropriate 
Table 8 The results of self-compacting concrete compressive strength

\begin{tabular}{|c|c|c|c|c|c|}
\hline $\begin{array}{l}\text { Maximum ratio } \\
\text { errors }\end{array}$ & $\begin{array}{c}\text { Average ratio } \\
\text { error }\end{array}$ & $\begin{array}{c}\text { Correlation } \\
\text { coefficient }\end{array}$ & $\begin{array}{c}\text { Data usage in } \\
\text { model }\end{array}$ & Model & Technique \\
\hline 6.68 & 0 & 0.921 & Training & \multirow{2}{*}{$\mathrm{CS}=24.178+0.639 \mathbf{M K}-0.682 \mathbf{S F}+0.469 \mathbf{T}$} & \multirow{2}{*}{ Linear regression } \\
\hline 8.67 & 0.04 & 0.865 & Testing & & \\
\hline 7.04 & 0 & 0.956 & Training & \multirow{2}{*}{$\mathrm{CS}=18.131+0.489 \mathbf{M K}-0.469 \mathbf{S F}+0.011 \mathbf{T}^{2}$} & \multirow{2}{*}{$\begin{array}{l}\text { Nonlinear } \\
\text { regression }\end{array}$} \\
\hline 7.29 & 0.32 & 0.929 & Testing & & \\
\hline
\end{tabular}

CS: Compressive strength (MPa), MK: Metakaolin percentage, SF: Silica fume (SF) percentage, T: Age of specimen at the testing time

relationship between the percentage of metakaolin, Silica fume (SF) silica and the specimen age during the compressive strength test as variable inputs and the compressive strength is used as variable output. For this purpose, from 85 possible cases for mentioned variables with 0.32 water-cement ratio, 43 cases were used for model training, and the rest 42 cases were used for the accuracy assessment of extracted models. Several relationships were considered, and the best of them was chosen according to the correlation coefficient $\mathrm{R}^{2}$.

The variable inputs and extracted models details are shown in Table 8. The presented models' correlation coefficient value were about 1 and have few relative error, as shown in the Table 8 . This fact indicates that the chosen variable inputs are appropriate and makes changes in compact resistance in a regular way. In other words, in fact the compressive strength resistance doesn't have a linear relationship with age and Silica fume (SF), but a complicated one. In addition, in nonlinear models the correlation coefficient factor of training model samples and testing model samples don't contain remarkable difference. Finally, the second model shown in the Table 8 is offered for compact resistance estimation of self-compacted concrete.

\section{Conclusions}

In this paper, the effect of combination of silica fume and metakaolin on self-compacted concrete properties was investigated by experimental and analytical approaches. The following conclusions can be drawn from the outcomes of this research.

\section{References}

[1] Kou, S. C., Poon, C. S. "Properties of self-compacting concrete prepared with coarse and fine recycled concrete aggregates", Cement and Concrete Composites, 31(9), pp. 622-627, 2009.

https://doi.org/10.1016/j.cemconcomp.2009.06.005

[2] Nassar, R.-U.-D., Soroushian, P. "Strength and durability of recycled aggregate concrete containing milled glass as partial replacement for cement", Construction and Building Materials, 29, pp. 368-377, 2012.

https://doi.org/10.1016/j.conbuildmat.2011.10.061
1. The use of Silica fume (SF) caused a higher compressive strength than control sample strength. The compressive strengths were increased due to increasing Silica fume percentage and also the compressive strengths were increased by using metakaolin up to $15 \%$ of total cement mass. The rate of increasing of compressive strengths of specimens containing Silica fume and metakaolin at different ages were increased up to $27 \%$ comparing to that of control specimens.

2. Compressive strength and Silica fume and metakaolin relationships are linear and that strength and time relationship is nonlinear. The compressive strengths of metakaolin containing 5 to $20 \%$ were increased up to $21 \%$.

3. The use of Silica fume and metakaolin had the minor and major effect on increasing tensile strength, respectively.

4. The water absorption was decreased up to $18.5 \%$ by gradually increasing only metakaolin or Silica fume up to $20 \%$, this reduction can be more remarkable up to $40 \%$ as the concrete gets older particularly mixing silica fume and metakaolin.

5. The higher compressive and tensile strengths were obtained by using $15 \%$ combined pozzolan $(7.5 \%$ metakaolin and $7.5 \%$ Silica fume), suggested as the best percentage of substitution.

6. Non-linear multiple regression methods to better evaluate multiple linear regression of self-compacting concrete compressive strength and provide good precision can be achieved using this model compressive strength.

[3] Shi, C., Zheng, K. "A review on the use of waste glasses in the production of cement and concrete", Resources, Conservation and Recycling, 52(2), pp. 234-247, 2007.

https://doi.org/10.1016/j.resconrec.2007.01.013

[4] Wang, H.-Y., Huang, W.-L. "A study on the properties of fresh selfconsolidating glass concrete (SCGC)", Construction and Building Materials, 24(4), pp. 619-624, 2010.

https://doi.org/10.1016/j.conbuildmat.2009.08.047 
[5] Alyamaç, K. E., Ince, R. "A preliminary concrete mix design for SCC with marble powders", Construction and Building Materials, 23(3), pp. 1201-1210, 2009.

https://doi.org/10.1016/j.conbuildmat.2008.08.012

[6] Shi, C., Wu, Y. "Mixture proportioning and properties of self-consolidating lightweight concrete containing glass powder", ACI Materials Journal, 102(5), pp. 355-363, 2005.

[7] Aiswarya, S., Prince Arulraj, G., Dilip, C. "A Review on Use of Metakaolin in Concree", International Journal of Innovative Research in Science, Engineering and Technology, 3(3), pp. 592597, 2013.

[8] Mahajan, S., Singh, D. "Fresh and Hardened Properties of Self Compacting Concrete Incorporating Different Binder Materials", International Journal of Emerging Technology and Advanced Engineering, 3(12), pp. 689-693, 2013.

[9] Madandoust, R., Mousavi, S. Y. "Fresh and hardened properties of self-compacting concrete containing metakaolin", Construction and Building Materials, 35, pp. 752-760, 2012. https://doi.org/10.1016/j.conbuildmat.2012.04.109

[10] Güneyisi, E., Gesoğlu, M., Mermerdaş, K. "Improving strength, drying shrinkage, and pore structure of concrete using metakaolin", Materials and Structures, 41, pp. 937-949, 2008. https://doi.org/10.1617/s11527-007-9296-z

[11] Dhinakaran, G., Thilgavathi, S., Venkataramana, J. "Compressive strength and chloride resistance of metakaolin concrete", KSCE Journal of Civil Engineering, 16(7), pp. 1209-1217, 2012. https://doi.org/10.1007/s12205-012-1235-z

[12] Dalvand, A., Sharbatdar, M. K., Kheyroddin, A., Nikui, A. "Assessment of statistical variations in experimental impact resistance and mechanical properties of silica fume concrete", Scientia Iranica A, 21(5), pp. 1577-1590, 2014. [online] Available at: http://scientiairanica.sharif.edu/article_1749.html [Accessed: 25 February 2020]

[13] Nikoui, A., Dalvand, A., Sharbatdar, M. K., Kheyroddin, A. "Experimental and Statistical Investigation on Mechanical Properties and Impact Resistance of Synthetic Fiber Reinforced Concrete", Iranian Journal of Science and Technology, Transactions of Civil Engineering, 39(C2+), pp. 449-468, 2015. https://doi.org/10.22099/ijstc.2015.3513

[14] Naderpour, H., Rafiean, A. H., Fakharian, P. "Compressive strength prediction of environmentally friendly concrete using artificial neural networks", Journal of Building Engineering, 16, pp. 213-219, 2018.

https://doi.org/10.1016/j.jobe.2018.01.007
[15] Hassan, A. A. A., Lachemi, M., Hossain, K. M. A. "Effect of Metakaolin on the Rheology of Self-Consolidating Concrete", In: Khayat, K. H., Feys, D. (eds.) Design, Production and Placement of Self-Consolidating Concrete, Springer, Dordrecht, Netherlands, 2010, pp. 103-112.

https://doi.org/10.1007/978-90-481-9664-7_9

[16] Vejmelková, E., Keppert, M., Grzeszczyk, S., Skaliński, B., Černý, R. "Properties of self-compacting concrete mixtures containing metakaolin and blast furnace slag", Construction and Building Materials, 25(3), pp. 1325-1331, 2011.

https://doi.org/10.1016/j.conbuildmat.2010.09.012

[17] Kheyroddin, A., Abbasi Rasht Abadi, M., Fakharian, P. "Study the Setting Time of Fresh Concrete Containing Glass Powder and Metakaolin using Ultrasonic Method", presented at 1st National Conference on Applied Research in Structural Engineering and Construction Management, Tehran, Iran, Sept. 22-23, 2016.

[18] Burgos, D., Guzmán, A., Hossain, K. M. A., Delvasto, S. "The use of a volcanic material as filler in self-compacting concrete production for lower strength applications", Materiales de Construcción, 67(325), Article ID: e111, 2017. https://doi.org/10.3989/mc.2017.09315

[19] Cifuentes, H., Ríos, J. D., Gómez, E. J. "Effect of mix design on the size-independent fracture energy of normal- and high-strength self-compacting concrete", Materiales de Construcción, 68(329), Article ID: e144, 2018. https://doi.org/10.3989/mc.2018.00717

[20] Rozas, F., Castillo, A., Martínez, I., Castellote, M. "Guidelines for assessing the valorization of a waste into cementitious material: dredged sediment for production of self compacting concrete", Materiales de Construcción, 65(319), Article ID: e057, 2015. https://doi.org/10.3989/mc.2015.10613

[21] Akinpelu, M., Adedeji, A. A. "Structural Response of Reinforced Self-Compacting Concrete Deep Beam using Finite Element Method", Journal of Soft Computing in Civil Engineering, 2(1), pp. 36-61, 2018. https://doi.org/10.22115/scce.2018.50115

[22] EFNARC "Specification and Guidelines for Self-Compacting Concrete", European Federation of National Associations Representing for Concrete, Farnham, UK, 2002. [online] Available at: http://www.efnarc.org/pdf/SandGforSCC.PDF [Accessed: 25 February 2020] 